BLS 33, No 1 2007. DOI: http://dx.doi.org/10.3765/bls.v33i1.3538

(published by the Berkeley Linguistics Society and the Linguistic Society of America)

\title{
Double-subject Sentences, Double-dimension Semantics
}

\author{
WILLIAM SALMON \\ Yale University
}

\section{Introduction}

This paper looks at one topic-comment construction in spoken Brazilian Portuguese (BP). The construction is similar to what Li and Thompson $(1976,1981)$ have called double-subject sentences (DSS) for Mandarin and other topicprominent languages. (1a) is a prototypical example of the BP construction in question, and a Mandarin example follows in (1b).

a. Peixe, sardinhas são deliciosas.
'Fish, sardines are delicious.'

b. Zhèi ge nŭhái yănjing hěn dà. [Li and Thompson 1981:4.19]

'That girl, eyes are very big.'

The BP double-subject sentence is syntactically composed of an initial NP followed by an NP and a VP. The initial NP (NP1) contains topic information, and the rest of the construction bears a comment related to that topic information.

The DSS have received very little attention in traditional Brazilian Portuguese grammars or in linguistic literature, so part of this paper must be descriptive. The greater part of the paper, however, explores how the topic NPs might be accounted for within the multidimensional semantics of Potts (2005).

\section{Background and Description of Brazilian Double-subject Sentences}

The DSS occur normally in informal, spoken Brazilian Portuguese. The construction seems to have been first mentioned in Pontes (1987), and Perini dedicates a brief section to it in his 2002 reference grammar of BP.

We can get a basic idea of the DSS grammar through a comparison to Li and Thompson's (1976) rendering of its Mandarin counterpart. The essential features discussed below are: the requirement of a part-whole relationship with NP1 and the comment sentence; NP1 must be definite or generic; NP1 lacks selectional relations with the main verb; there must be an intonational break between NP1 and the comment sentence. For the most part, the BP sentences pattern here exactly as with the Mandarin. 
As do the Mandarin topics, the BP topics must bear a part-whole or a hyponymy relationship, which is seen in the subcategory sardinhas of the more general peixe. The definiteness/generic requirement can be seen in NP1 of (2) and (3) respectively.

(2) Peixe, sardinhas são deliciosas.

'Fish, sardines are delicious.'

(3) Esse presidente, o imposto está cada vez mais alto. [Perini §39.4]

'This president, taxes are getting higher and higher.'

(4) Flores, a Maria gosta de tulipas. [Flannery and Kuong (2)]

flowers, the Maria like.3.sg. tulips

'Flowers, Maria likes tulips.'

In (4) we can see the lack of selectional relations with the verb. The topic Flores 'flowers' is plural, while the verb gosta 'likes' agrees with a singular subject Maria.

Finally, the intonational break between NP1 and the following sentence is an important feature to consider, as it will play an important role below in the discussion of the DSS and Potts's multidimensional semantics. This break is obligatory in all of the BP sentences. This contrasts with the Mandarin sentences, in which an intonational break need not be present in fast speech.

We can now turn to the semantics of Potts (2005) and what it can tell us about the DSS.

\section{Multidimensional Semantics}

Potts (2005) develops a two-dimensional semantics with an eye toward Grice's (1989) conventional implicature (CI). However, he makes very clear that he intends his semantics to account for many kinds of multidimensional data that have not previously been discussed as CIs, such as non-restrictive relatives, sentence adverbs, honorifics, epithets, in addition to other kinds of expressive

\footnotetext{
${ }^{1}$ Flannery and Kuong (2004) claim that the DSS can be indefinite in BP. However, the examples they cite in support of this seem to actually be generics, as in (i) and so are not counterexamples. [Flannery and Kuong's (1)]

(i) Animais de estimação, eu falei com aquele menino sobre cachorros ontem. 'Pets, I talked about dogs with that kid yesterday.'

It should be mentioned, however, that indefinite NPs do seem possible in the NP1 position as long as they receive a specific reading. So, it appears that definiteness alone is not a sufficient description.
} 
content. $^{2}$ In fact, he purposefully bypasses the traditional CI data such as but, therefore, and even ${ }^{3}$ in favor of the supplements and expressives.

The claim is that various grammatical elements contribute multidimensional information, but that this multidimensional information must stand in a certain relation to a primary assertion: viz., it is a comment upon a primary assertion, or it helps the hearer to better understand a primary assertion. This seems exactly relevant to the DSS, and so the final part of this paper attempts to show that despite some initial hesitation, Potts's semantics suggests a stimulating place to locate these traditionally illusive data.

Potts (2005:2.10) distills various passages from Grice (1989), arriving at what he terms the "abstract properties" of CIs given below in (5), and a large portion of his work is spent defining his various CI data against this definition.

a. CIs are part of the conventional meaning of words

b. CIs are commitments and thus give rise to entailments

c. These commitments are made by the speaker of the utterance 'by virtue of the meaning of the words' he chooses

d. CIs are logically and compositionally independent of what is said (in the favored sense)' i.e., independent of the at-issue entailments

Potts assumes, following Bach (1999) and others, that a single sentence can express multiple propositions, and he suggests that a sentence containing a CI actually expresses two propositions: the first a primary one, which contains the important or "at issue" information, and then a secondary one, which contains information that has been backgrounded but that helps the hearer to understand the first. So, according to Potts, (6a) expresses the primary assertion in (6b) as well as the secondary (and false) assertion in (6c) [Potts's (2.38)]:
a. Lance Armstrong, an Arkansan, has won the 2003 Tour de France!
b. Lance Armstrong has won the 2003 Tour de France.
c. Lance Armstrong is an Arkansan.

My primary interest for this paper is in Potts's formulation of the two-tiered semantics. On the lower level Potts places primary assertions, represented in (6b). The upper level contains secondary assertions like (6c), and it is concerned with directing the discourse, or allowing the speaker to comment upon her assertion. It is this upper level that is relevant to discussion of the DSS.

Crucial to Potts's analysis of primary and secondary assertions is what he refers to as comma intonation. Potts depends heavily on this intonational break to distinguish CI content from primary asserted content. The comma intonation

\footnotetext{
${ }^{2}$ Whether or not Grice would have considered the non-restrictive relatives, sentence adverbs, etc., to be conventional implicatures, I will leave aside for the time being.

${ }^{3}$ Potts does not consider these traditional data to be CIs. This is based on his claim that they do not satisfy his requirement that CIs be speaker-oriented. For Potts, then, Grice's definition of CIs is a valid concept, but it just picks out different data from those Grice originally discussed.
} 
marks a shift from at-issue content to CI content, or from the lower to the upper level of Potts's two-tiered semantics. As I have discussed above, the Brazilian DSS must always be set off by such an intonational break. This suggests that they are not semantically coordinate with the primary assertion, and it provides an immediate parallel to Potts's data. What remains then is the question whether Potts's definition in (5) above can pick out the DSS in addition to the supplements that are the focus of his work. I suggest that it does so easily. First, however, there is a potential point of contention looming that needs to be dealt with.

\subsection{Discourse-newness and Potts CIs}

Potts requires his CIs to contribute discourse-new information. This he does in order to set CIs apart from presupposition, which has long had a confusing relationship with conventional implicature in the semantics and pragmatics literature. ${ }^{4}$

Now, topic-hood has traditionally been discussed in terms of shared information, givenness, old information, and so forth, and this seems immediately counter to Potts's requirement that CIs be discourse-new. However, notions like familiarity and shared knowledge are notoriously slippery. For example, some object or event could be familiar or shared knowledge to discourse participants yet not be the immediate topic of conversation. This shared information could then be brought to the forefront of the conversation, and even though the information was previously known, it would then be considered discourse-new. I think this is at least part of the potential problem that I discuss in the next few paragraphs. Essentially, Potts seems to use "not part of the common ground" and "discoursenew" interchangeably. ${ }^{5}$ But as I suggest for the DSS, such usage is a bit coarse, as DSS generally do contribute information that is somehow part of a prior common ground. At the same time, though, DSS need to be used such that they are contributing a kind of discourse-new information, or else they are redundant.

There are a couple of things we can do here to show that the DSS are not in conflict with this part of Potts's proposal. First, we can illustrate that while the DSS do contain previously known information, they are generally used in situations where this information will not be redundant. Second, we can easily show that the information in Potts's examples can be characterized the same way: that is, the supplements can be both previously known and discourse-new. Let's look first at some of Potts's examples, in which he suggests supplements are required to contribute discourse-new content.

Here is Potts's (2.13a), reproduced here as (7a), as well as an indefinite version of the same nominal appositive [Potts's (4.2a)] reproduced here as (7b). Both of these he considers to be good CIs by his definition.

a. Ames, the former spy, is behind bars.

\footnotetext{
${ }^{4}$ See Karttunen and Peters (1979), and Chierchia and McConnell-Ginet (2000), on CIs as presuppositions.

5 "CI expressions usually offer information that is not part of the common ground when they are uttered" (33). And, "the constructions are united in contributing discourse-new, speaker-oriented entailments: CIs" (13).
} 


\section{Double-subject Sentences, Double-dimension Semantics}

b. Ames, a successful spy, is now behind bars.

According to Potts, "former spy" should be discourse-new, deemphasized information. But what if we tinker with Potts's example a little bit, as in (8), below?

a. Ames, you know, the former spy, is behind bars.

b. Ames, the guy I was just telling you about, is a former spy.

In (8a), the speaker must assume the hearer is already familiar with the fact that Ames is a former spy. This is suggested by the consensual marker you know as well as by the use of the definite article. In these examples the speaker seems to be reactivating "former spy" rather than introducing novel information.

In a BP double-subject sentence, NP1 must be something the hearer has some familiarity with, and the familiarity must be relatively proximal. However, the restrictions run the other way too. If it is obvious what the discourse topic is, it can be redundant and awkward to use the DSS.

Consider the following scenario. Two people are talking about Mr. Jones's biology class and the fact that the students had just taken an exam. As a result, the class and the exam are completely activated in the discourse. In this case, it is not necessary to use the DSS in (9a) and to do so would seem repetitive. The speaker could instead just assert the non-DSS (9b).
a. Classe da sra. Jones, todo mundo repetiu de ano. 'Mr Jones's class, every boy failed the exam.'
b. Todo mundo repetiu de ano. 'Every boy failed the exam.'

We can see an English correlate to this kind of redundancy in the as for constructions in (10):

(10) John: I'm going to The Salt Lick for some ribs. I love that place.

Ted: \#Yeah. As for The Salt Lick, I think it's pretty good too.

Grady: Yeah. I think it's pretty good too.

Ultimately then, the DSS do not seem in conflict with Potts's discourse-new requirement, and we can return to his definition of CIs to see that it does seem to pick out the DSS as a kind of CI meaning.

\subsection{CIs are Part of the Conventional Meaning of Words}

It is clear that what the DSS assert depends directly on the semantics of the words that compose them. There is no mystery with this requirement, no inference or implicature necessary. It is by virtue of the semantic reference of NP1, along with the syntactic position and comma intonation, that the DSS establishes or (re)activates a relation with a context. 
In addition, the fact that there needs to be a part-whole relation between the topic and grammatical subject, no matter how dependent on context, further suggests that there are restrictions which depend on the semantic content of NP1.

\subsection{CIs are Commitments and thus Give Rise to Entailments}

This part of the definition is also straightforward in that it is not possible to deny what is contributed by NP1. Again, there is no sense in which "fish" is used to implicate something other than fish or where anything is used non-literally in either of the examples below. If by the use of the DSS one is meaning to reintroduce or reactivate a topic, it follows that the reactivated topic cannot then be denied.

(11) Peixe, sardinhas são deliciosas. Mas, eu não estou falando sobre peixe.

'Fish, sardines are delicious. \#But, I am not talking about fish.'

Further, if we take a standard DSS like (12a) and insert a relative clause containing information similar to the topic, the resulting redundancy is extremely awkward, as in (12b).

a. Peixes, sardinhas são deliciosas.

'Fish, sardines are delicious.'

b. \#Peixes, sardinhas, que são um tipo de peixe, são deliciosas.

'Fish, sardines, which are a kind of fish, are delicious.'

\subsection{CIs are Commitments Made by the Speaker of the Utterance}

This part of Potts's definition is a little harder to illustrate with the DSS. The primary means of testing for speaker orientation is through indirect speech reports, embedding under verbs like say. However, for the DSS, embedding of any kind does not work, as the topics have a strict requirement to be sentenceinitial.

Potts demonstrates that under embedding, the content of supplements and epithets becomes relativized to the speaker of the new construction and so these forms seem to follow the current utterance rather than the one being reported. That is, those constructions are syntactically embeddable, while semantically unembeddable. However, with the DSS, it is just not possible to embed them at all. They are syntactically unembeddable.

For example, if we embed the topic construction in (13a), as in (13b), it is necessary to insert an additional pause after dourado 'dolphin', the grammatical subject of (13a). This changes the meaning and the syntax dramatically. In the embedded (13b), Peixe 'fish', which was formerly the topic, now has become the grammatical subject, while dourado has become a nominal appositive.

a. Peixe, dourado é o melho.

'Fish, dolphin is the best.' 


\section{Double-subject Sentences, Double-dimension Semantics}

b. Gustavo disse que o peixe, dourado, é o melho.

'Gus said that fish, dolphin, is the best.'

Without the additional pause, in (13b), the sentence would just be ungrammatical. As it stands though, it is no longer the kind of construction we have been interested in in this paper.

Thus, we cannot embed the DSS directly. But this is not too surprising, as NP1 is essentially a kind of shorthand that requires contextual information and specific syntactic marking to be fully saturated. Thus, evidence for this part of Potts's requirement is a bit more difficult to find.

We can find indirect evidence for speaker-orientedness, though, in the embedding behavior of the as for construction. Here, the topic marker is shifted to a parenthetical position within the sentence.

\section{Mary: I love all kinds of meat. My favorite is beef flank-steak. Also I like pork butt roast. And sardines, as for fish, are delicious.}

The parenthetical as for fish has the effect of changing the topic in (14) just as it does in initial position in (15).

\section{Mary: I love all kinds of meat. My favorite is beef flank-steak. Also I like} pork butt roast. As for fish, sardines are delicious.

And, as for is easily embedded in English and BP with the desired speakeroriented interpretation.

a. John said that sardines, as for fish, are delicious.

b. João disse que sardinhas, quanto ao peixe, são deliciosas.

Thus, we can see that in the as-parenthetical constructions it does seem possible to retrieve speaker-oriented meaning. ${ }^{6}$

This is not conclusive evidence, as the relevant constituent in the DSS is sentence-initial, but it is at least encouraging evidence. Interestingly, Potts faces a similar difficulty with some of his data, which we will turn to next.

For Potts, some of the more problematic data are his supplementary adverbs, which are a special class of supplements. These face similar difficulty in embedding, and we can draw support from a comparison of the behavior of the DSS and the supplementary adverbs.

Utterance modifiers ${ }^{7}$ such as confidentially, frankly, between you and me, etc., pattern just like the DSS, as they do not embed and they "are restricted to matrix occurrences because they require arguments that have main clause force" (Potts 147). This can be seen in (17a-b) [Potts's (4.140a-b)].

a. Confidentially, Al's wife is having an affair.

\footnotetext{
${ }^{6}$ C.f. Lambrecht (1990) on reversibility of topic constituents in Mad Magazine sentences.
}

${ }^{7}$ See Bach (1999) for a lengthy discussion of this kind of utterance modifier. 
b. \#Bill said that, confidentially, Al's wife is having an affair.

In (17a), Potts suggests the adverb bears a relation between the speaker and the utterance: namely, that the utterance is being made confidentially. This is clearly not the case in (17b), which if anything, means Al's wife is having an affair confidentially. But even this reading is not forthcoming. So we can find a sort of parallel between the utterance modifiers in (17a-b) and the attempt at embedding DSS in (13a-b): both in their syntactic behavior under embedding and in the way their semantic contributions change in the embedded sentences.

It is difficult to make claims about the DSS data and Potts's speaker-oriented requirement. But, there is more to say about this aspect of Potts's proposal generally. Bach (2006:493) correctly observes that the nature of speakerorientedness varies widely between the expressives and the supplements of Potts's data, with expressives being "speaker-oriented in a more radical way" than supplements. As Bach suggests, expressive content is a relation that is strictly between the speaker and the utterance, while the content of supplements can be believed by anyone. This is a difference that Potts does not address. ${ }^{8}$

Thus, while the DSS do not meet this part of Potts's definition as well as they might, they seem to be at least marginally speaker-oriented, and their behavior is comparable to that of Potts's utterance modifiers.

\subsection{CIs are Logically and Compositionally Independent of What is Said}

According to Potts, CI content should not affect the basic truth of the primary assertion. ${ }^{9}$ Thus consider (18) [Potts's (2.38)], which contains a supplement that contributes false information.

$$
\text { Lance Armstrong, an Arkansan, has won the } 2003 \text { Tour de France! }
$$

Armstrong is, of course, from Texas, not Arkansas, but this does not prevent us from recovering from the utterance that Lance Armstrong did in fact win the 2003 Tour de France.

As was demonstrated above, the BP DSS have no selectional relations with the verb of the primary assertion. There need only be a very loose semantic relation with the grammatical subject, which is consistent with Potts's supplements. Crucially though, this relation doesn't seem to have an effect on the

\footnotetext{
${ }^{8}$ See also Karttunen and Zaenen (2005) for other potentially problematic issues arising for speaker-oriented claims.

${ }^{9}$ This claim is less obvious if the appositive is a full clause such as in (i).
}

(i) Lance Armstrong, who is an Arkansan, has won the 2003 Tour de France.

Similarly, if the appositive is a little more outrageous, judgments will differ on the truth of the primary assertion, such as in (ii).

(ii) Steve Anderson, the defensive tackle for the Dallas Cowboys, is chair of the linguistics department at Yale. 


\section{Double-subject Sentences, Double-dimension Semantics}

semantics of the primary assertion. It instead is relevant to felicity conditions for NP1 itself. We can remove the topic, and the semantics of the primary assertion do not change: sardines are still delicious whether they're linked to the rest of the discourse via the topic or not. While removing the topic might result in an utterance that is infelicitous or misplaced in context, it does not result in one that is semantically ill-formed.

We can take a quick example from Potts to further illustrate the independence of the content of NP1 from the at-issue meaning. Potts demonstrates that if assertions containing speaker adverbs are denied, it is the content of the primary assertion that is denied, not that of the speaker-oriented adverb. Consider (19) [Potts's (3.17)].

Unfortunately, I was home when my parole officer called.

According to Potts, if the hearer responded No to (19) she would be denying only that the speaker was home when the parole officer called, not the unfortunateness of the situation.

The BP examples we have seen thus far pattern the same way.

Churasco, carne de vaca é delicioso.

'Barbecue, beef is delicious.'

If the hearer were to respond Não to (20), she would not be denying the relation between beef and barbecue. Rather, she would be denying that beef is delicious. Similarly, if the hearer queried Por que? she would be asking why beef was delicious, not why a relation holds between beef and barbecue. So it seems quite clear that the content of NP1 and its relation to the comment is not a part of the primary assertion that beef is delicious.

Thus it seems the BP double-subject sentences pattern in accordance with the criteria Potts sets up to define his CI data. Of the four parts of the definition given in (5), only the speaker-oriented requirement gives us any pause. However, as I show in $\S 2.4$, there is indirect evidence that suggests the BP data can be considered speaker-oriented in the way Potts requires.

\section{Conclusion}

The BP double-subject sentences are quite similar to those in Mandarin, but there are key differences: most notably, the stricter requirement of an intonational break for the BP. Thus, the BP double-subject sentences seem a better candidate for exploring Potts's multidimensional semantics.

In the past this kind of construction has been considered a discourse-level or information structure phenomenon, to the extent that it has been considered at all. This paper attempts to place a topic-comment type construction next to other kinds of multidimensional meaning - supplements and expressives, perhaps the lexical CI triggers. If successful, we can begin to ask a whole new range of questions of their semantic and pragmatic relations to the larger structure of a discourse and efficient, felicitous communication. 


\section{References}

Bach, Kent. 1999. The Myth of Conventional Implicature. Linguistics and Philosophy 22(4):367-421.

Bach, Kent. 2006. Review of The Logic of Conventional Implicatures. Journal of Linguistics 42(2):490-495.

Chierchia, Gennaro and Sally McConnell-Ginet. 2000. Meaning and Grammar: An Introduction to Semantics. 2nd ed. Cambridge, MA: MIT Press.

Grice, Paul. 1989. Studies in the Way of Words. Cambridge, MA: Harvard University Press.

Karttunen, Lauri and Annie Zaenen. 2005. Veridicity. Ms. Palo Alto Research Center.

Kuong, Io-Kei Joaquim and Mércia Flannery. 2004. Frame-Setting Topic and the Left Periphery in Syntax. Poster presented at GURT 2004, Georgetown University. <http://complingtwo.georgetown.edu/ gurt/abstracts/01.htm>.

Lambrecht, Knud. 1990. "What, me worry?"-Mad Magazine Sentences Revisited. Proceedings of Berkeley Linguistics Society, Vol. 16.

Lambrecht, Knud. 1994. Information Structure and Sentence Form: Topic, Focus and the Mental Representations of Discourse Referents. Cambridge: Cambridge University Press.

Li, Charles and Sandra Thompson (eds.). 1976. Subject and Topic. New York: Academic Press.

Li, Charles and Sandra Thompson. 1976. Subject and Topic: A New Typology of Language. In C.N. Li and S.A. Thompson (eds.).

Li, Charles and Sandra Thompson. 1981. Mandarin Chinese: A Functional Reference Grammar. Berkeley: University of California Press.

Perini, Mário A. 2002. Modern Portuguese: A Reference Grammar. New Haven: Yale University Press.

Pontes, Eunice. 1987. O Tópico no Português do Brasil. Campinas, SP: Pontes.

Potts, Christopher. 2005. The Logic of Conventional Implicature. Oxford: Oxford University Press.

William Salmon

Yale University

Linguistics Department

370 Temple, Rm 201

New Haven, CT 06511

william.salmon@yale.edu 